\title{
A novel reutilization method for waste printed circuit boards as flame retardant and smoke suppressant for poly (vinyl chloride)
}

\author{
Fu-Rong Xiu ${ }^{\mathrm{a}, *}$, Huiwei Weng ${ }^{\mathrm{a}}$, Yingying $\mathrm{Qi}^{\mathrm{a}}$, Gending $\mathrm{Yu}^{\mathrm{a}}$, Zhigang Zhang ${ }^{\mathrm{a}}$, \\ Fu-Shen Zhang ${ }^{\mathrm{b}}$ \\ a College of Ecological Environment and Urban Construction, Fujian University of Technology, Fuzhou 350108, People's Republic of China \\ ${ }^{\mathrm{b}}$ Research Center for Eco-Environmental Sciences, Chinese Academy of Sciences, Beijing 100085, People's Republic of China
}

\section{H I G H L I G H T S}

- We report a novel electronic waste-based flame retardant for PVC.

- The SCWO-treated PCBs significantly improves the flame retardancy of PVC.

- The flame retardant mechanism of SCWO-treated PCBs was studied.

- Appropriate amount flame retardant does not degrade the mechanical property of PVC.

\section{A R T I C L E I N F O}

\section{Article history:}

Received 17 January 2016

Received in revised form 18 April 2016

Accepted 30 April 2016

Available online 2 May 2016

\section{Keywords:}

WEEE

Waste PCB

Reutilization

Flame retardant

Smoke suppressant

\begin{abstract}
A B S T R A C T
In this study, a novel reutilization method for waste printed circuit boards (PCBs) as flame retardant and smoke suppressant for poly (vinyl chloride) (PVC) was successfully testified. A supercritical water oxidation (SCWO) process was applied to treat waste PCBs before they could be used as flame retardants of PVC. The results indicated that SCWO conditions had a significant effect on the flame retarding and smoke suppressing properties of waste $\mathrm{PCBs}$ for $\mathrm{PVC} . \mathrm{Cu}_{2} \mathrm{O}, \mathrm{CuO}$, and $\mathrm{SnO}_{2}$ were the main active ingredients in waste PCBs-derived flame retardants. A conversion of $\mathrm{Cu}$ elements $\left(\mathrm{Cu}^{0} \rightarrow \mathrm{Cu}^{+} \rightarrow \mathrm{Cu}^{2+}\right)$ during SCWO process with the increase of reaction temperature was found to be the key influence factor for the flame retarding properties of SCWO-treated PCBs. The experiment results also showed that there was a synergistic effect of flame retardancy between $\mathrm{Cu}^{+}$and $\mathrm{Cu}^{2+}$. After the optimized SCWO treatment, SCWO-treated PCBs significantly improved the flame retardancy and smoke suppression of PVC. Limiting oxygen index (LOI) and char yield (CY) increased with increasing SCWO-treated PCBs content in PVC, while smoke density rating (SDR) and maximum smoke density (MSD) decreased markedly. The mechanical properties of PVC samples were influenced in different degree by adding different content SCWO-treated PCBs.
\end{abstract}

(C) 2016 Elsevier B.V. All rights reserved.

\section{Introduction}

In recent years, the treatment and recycling of amounts of waste electric and electronic equipment (WEEE) have attracted the most attention of the researchers around the world and the public [1]. As the fundamental part in most WEEE, waste printed circuit boards (PCBs) consisted of metals and nonmetal portions such as copper, tin, lead, gold, silver, and brominated resin [2-5]. In general, waste PCBs can be regarded as resources from the economic perspectives. Currently, many technologies, such as pyrometallurgy

\footnotetext{
* Corresponding author.

E-mail addresses: xiu_chem@hotmail.com, xiu_chem@163.com (F.-R. Xiu).
}

[6], hydrometallurgy [7], bio-technology [8], and mechanical methods $[9,10]$, have been proposed for the treatment of waste PCBs. Mechanical method can be used as an effective pre-treatment method for the separation of metals and nonmetal portions. Pyrolysis of waste PCBs was studied intensively for decomposition of resin materials and recovery of organic products [11,12], however, the formation of secondary pollution such as dioxins and furans is difficult to be disposed of [13]. Hydrometallurgical process is an effective route to recover metals from waste PCBs. However, hydrometallurgical process generally includes multistep leaching, separation, and purification, which lead to the generation of a large amount of hazardous waste water and sludge containing heavy metals [14]. Hence, the study of novel reutilization method for waste PCBs becomes increasingly important. 
Recently, researchers proposed a few novel "direct reutilization" strategies for the treatment of waste PCBs [14-17], which provided a new perspective for the study and application of WEEE. An effective adsorbent for heavy metals was directly developed by using the nonmetal portions of waste PCBs [15-17]. Li et al. reported the direct application of metals portions in waste PCBs as a catalyst to degrade pyridine in Fenton-like reaction [14]. Hence, by directly taking full advantage of the physicochemical property of effective constituent contained in waste PCBs, the "direct reutilization" strategy is supposed to be a promising solution for waste PCBs treatment.

It is well known that copper, iron, and solder (tin and lead) are the primary metals in waste PCBs. These metals, especially copper, tin, and iron, have been reported to have the potential as flame retardants for polymer materials when they exist as oxides [18-20]. For instance, transition metal oxides can catalyze $\mathrm{HCl}$-elimination reaction of PVC, which can play a role of flame retardant in gas phase [19]. These metals provide a possibility for the waste PCBs to be regarded as flame retardants applying in polymer materials. In addition, waste PCBs may have good flame retardant performance because of the poly-metallic complex system may induce synergistic effect in flame retardant behavior. Flame retardants with poly-metallic, such as artificial synthesized compounded flame retardants with metallic oxide or metal chloride [21,22], or natural materials of kaolinite, montmorillonite, and talc [23-25] could usually enhance the flame retardancy of polymer materials. However, these metals especially the copper contained in waste PCBs exist mainly as zero-valent metal, which has no any flame retardant performance. The oxidation of metals contained in waste PCBs can be realized by a variety of methods, among which the simplest one is the combustion heat treatment [26]. However, a large amount of toxic air pollutants were generated during the combustion process. Recent researches indicated that supercritical water oxidation (SCWO) treatment could solve this problem for the reason that the toxic organic matters in waste PCBs could be degraded safely in SCWO process and the formation of toxic air pollutants could be eliminated at the same time [27-29]. It's worth noting that the metals contained in waste PCBs can also be oxidized during SCWO process due to the reaction of oxidation atmosphere. As far as we know, to date, no report is on applying directly waste PCBs as a flame retardants for polymer materials. The research in this aspect could provide a novel perspective for the "direct reutilization" strategy of waste PCBs.

In this study, the SCWO-treated waste PCBs were tested for the first time as a flame retardant and smoke suppressant for polymer materials with the aim of recycling these waste resources in a new "direct reutilization" strategy. Poly (vinyl chloride) (PVC) was selected as a model polymer material. The objectives of the present work are (1) to evaluate the effect of SCWO conditions on the speciation of metals contained in waste PCBs and the flame retardant mechanism of SCWO-treated waste PCBs, and (2) to investigate the influence of waste PCBs-derived flame retardant on the flame retardancy and smoke suppression of PVC such as limiting oxygen index (LOI), char yield (CY), smoke density rating (SDR), and maximum smoke density (MSD). In addition, the mechanical properties of PVC samples with SCWO-treated PCBs were also evaluated.

\section{Materials and methods}

\subsection{SCWO treatment of waste PCBs}

Waste PCBs used in this work were collected from discarded personal computer in Fujian University of Technology, China. Firstly, the components (relays, capacitors, etc.) were manually disassembled, then the waste PCBs were sent to comminute in a cutting mill
Table 1

Mass percent of metals in original waste PCBs and solid product obtained after SCWO process (wt.\%).

\begin{tabular}{llllll}
\hline Metal element & $\mathrm{C}_{0}$ & $\mathrm{C}_{1}$ & $\mathrm{C}_{2}$ & $\mathrm{C}_{3}$ & $\mathrm{C}_{4}$ \\
\hline $\mathrm{Cu}$ & 21.8 & 27.7 & 32.7 & 32.7 & 0.2 \\
$\mathrm{~Pb}$ & 1.1 & 1.4 & 1.7 & 1.7 & 0.1 \\
$\mathrm{Sn}$ & 4.8 & 6.1 & 7.2 & 7.2 & 15.1 \\
$\mathrm{Fe}$ & 2.3 & 2.9 & 3.4 & 3.4 & 0.01 \\
$\mathrm{Zn}$ & 3.5 & 4.4 & 5.2 & 5.2 & 0.01 \\
\hline
\end{tabular}

$\mathrm{C}_{0}$ : mass percent of metals in original waste $\mathrm{PCBs}$.

$\mathrm{C}_{1}$ : mass percent of metals in FR1.

$\mathrm{C}_{2}$ : mass percent of metals in FR2

$\mathrm{C}_{3}$ : mass percent of metals in FR3.

$\mathrm{C}_{4}$ : mass percent of metals in $\mathrm{HCl}$-treated FR3.

until the fractions reached particle size smaller than $4 \mathrm{~mm}$. Metal content in the original PCBs powder was determined by ICP-OES (OPTIMA 2000, PerkinElmer) after digestion according to a literature [30]. The analysis results are given in Table 1.

The SCWO treatment was conducted in a batch-type reactor made of 316 alloy, having an inner volume of $200 \mathrm{~mL}$. In a typical treatment, $5 \mathrm{~g}$ of PCBs sample, $50 \mathrm{~mL}$ of distilled water, and $40 \mathrm{~mL}$ of $\mathrm{H}_{2} \mathrm{O}_{2}$ solution ( $30 \mathrm{wt} . \%$ ) were introduced into the reactor. Three groups of experiments with different SCWO treatment conditions were performed: (1) $300^{\circ} \mathrm{C}, 10 \mathrm{MPa}, 30 \mathrm{~min}$; (2) $420^{\circ} \mathrm{C}$, $22 \mathrm{MPa}, 60 \mathrm{~min}$; (3) $460^{\circ} \mathrm{C}, 30 \mathrm{MPa}, 60 \mathrm{~min}$. The reaction condition of group (1) is subcritical water oxidation, while group (2) and (3) are supercritical water oxidation. The reactions were terminated by quenching the reactor in a cold water bath, then the obtained product was collected and centrifugated. After that, solid phase product was washed and dried in a vacuum desiccator for $24 \mathrm{~h}$. The obtained solid phase product from group (1)-(3) was marked as FR1, FR2, and FR3, respectively. Metal content in SCWO-treated PCBs was determined by ICP-OES (OPTIMA 2000, PerkinElmer) after digestion [30]. The bromine content in the FR1, FR2, and FR3 was measured by an oxygen combustion bomb-ion chromatography (IC, DionexICS2000, USA) according to a literature [31]. The structure of SCWO-treated PCBs were characterized by X-ray diffraction spectroscopy (XRD) at $50 \mathrm{kV}$ and $100 \mathrm{~mA}$ using $\mathrm{Cu} \mathrm{K \alpha}$ radiation $(\lambda=1.5418 \AA)$.

\subsection{Preparation of flame retarded PVC samples}

After SCWO treatment of waste PCBs, the obtained solid phase product was used as flame retardant in the preparation of PVC samples. Samples of PVC were prepared by mixing PVC with Dioctyl Phthalate (DOP), heat stabilizer, lubricant, coupling agent, and the flame retardant prepared from waste PCBs after SCWO treatment. The basic composition for all of the samples was as follows: PVC $100 \mathrm{phr}$ (parts per hundred resins), DOP $40 \mathrm{phr}$, stabilizer $3 \mathrm{phr}$, lubricant $1 \mathrm{phr}$, and some flame retardant prepared from waste PCBs. The dosage of flame retardant was controlled at $0,2,4,6$, 8,10 , and $12 \mathrm{phr}$, respectively. PVC samples were blended in a two-roll mill at $170^{\circ} \mathrm{C}$ for $10 \mathrm{~min}$, and then the samples were introduced into a flat vulcanizing machine to be compressed at $180^{\circ} \mathrm{C}$. The sheets with dimensions of $90 \mathrm{~mm} \times 6 \mathrm{~m} \times 3 \mathrm{~mm}$ were formed after compression. Testing samples were cut from the molded PVC sheets.

\subsection{Flame retardancy, smoke suppression, and mechanical properties testing of PVC samples with SCWO-treated PCBS}

The flame retardancy and smoke suppression of PVC samples in this study was determined by Limiting Oxygen Index (LOI), char yield (CY), smoke density rating (SDR), and maximum smoke density (MSD). The LOI method is a simple, convenient, fast, and 

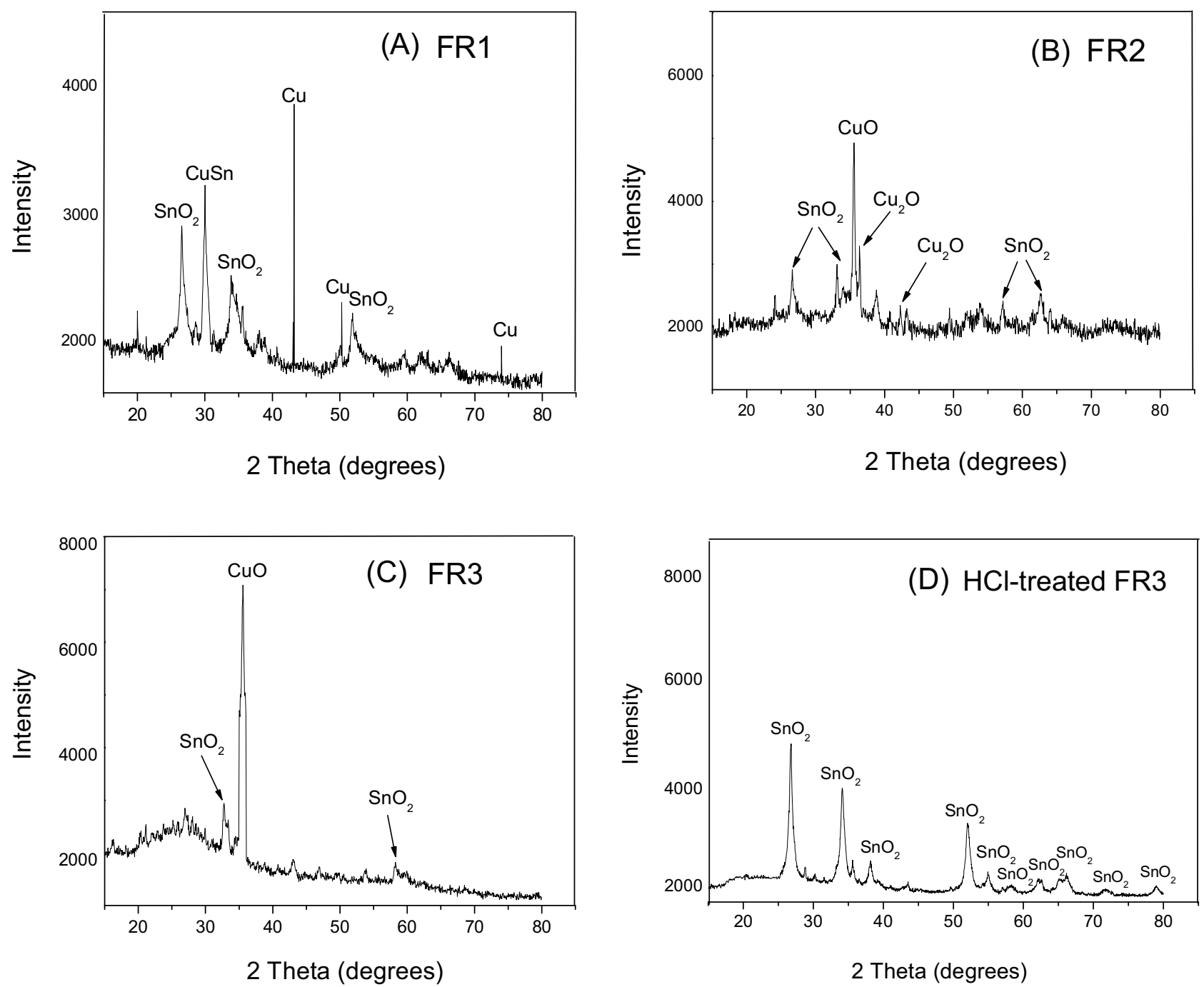

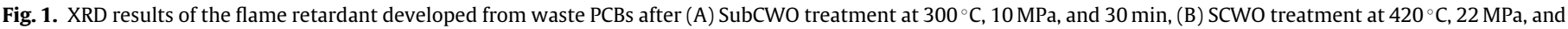
$60 \mathrm{~min}$, (C) SCWO treatment at $460^{\circ} \mathrm{C}, 30 \mathrm{MPa}$, and $60 \mathrm{~min}$, and (D) SCWO + $\mathrm{HCl}$ treatment (SCWO: $460{ }^{\circ} \mathrm{C}, 30 \mathrm{MPa}$, and $60 \mathrm{~min}$; $\mathrm{HCl}$ concentration: $1 \mathrm{M}$ )

effective method for the study of flame retardancy of plastic materials. It is a technique for measuring the Minimum Oxygen Concentration to Support Candle-Like Combustion of Plastics. The LOI value is the minimum amount of oxygen in an oxygen-nitrogen mixture required to support combustion over $3 \mathrm{~min}$ or until the testing sample is consumed for more than $5 \mathrm{~cm}$ from the top. LOI values were determined in accordance with ASTM 2863-2006 on a M605 LOI instrument (Qingdao, China). A higher LOI value indicates a greater efficiency for the flame retardant. The $\mathrm{CY}$ was calculated as follows:

$3 C Y=M_{1} / M_{2}$

where $M_{1}$ is the remaining weight of PVC sample after the treatment under nitrogen atmosphere at $400{ }^{\circ} \mathrm{C}$ for $40 \mathrm{~min}, M_{2}$ the weight of original PVC sample. A higher CY value indicates a greater efficiency for the flame retardant. The SDR and MSD of PVC samples were determined in accordance with ASTM D2843-1993 using a JCY-2 instrument (Nanjing, ShineRay, China). A lower SDR or MSD value indicates a greater efficiency for the smoke suppression.

Thermogravimetric analysis (TG) was carried out on a TGA-101 analyzer (Nanjing Dazhan, China) under air atmosphere at a heating rate of $20^{\circ} \mathrm{C} / \mathrm{min}$ and an air flow rate of $50 \mathrm{~mL} / \mathrm{min}$. The amount of PVC samples used for thermal analysis was $4-5 \mathrm{mg}$. The temperature range was from room temperature to $750^{\circ} \mathrm{C}$.
Tensile strength of PVC samples was determined on a tensile strength tester (HY-0230, Shanghai, China) at an extension speed of $10 \mathrm{~mm} / \mathrm{min}$. The elongation at break was calculated by the specific value of displacement to original length. Impact strength measurement of PVC samples was carried out on a ZY6148 impact strength tester (Guangdong, China) at impact speed of $2.9 \mathrm{~m} / \mathrm{s}$.

\section{Results and discussion}

\subsection{Effect of SCWO conditions on the speciation of metals contained in waste PCBs}

Mass percent of metals in original waste PCBs, FR1, FR2, and FR3 are presented in Table 1 . The metals contents in the aqueous phase after SCWO treatment of waste PCBs were also determined and the results indicated that the major metals such as $\mathrm{Cu}, \mathrm{Pb}, \mathrm{Sn}, \mathrm{Ni}, \mathrm{Fe}$, and Zn were not leached during SCWO process. According to previous studies [27-29], the resin material contained in waste PCBs could be effectively decomposed and removed by SCWO treatment, so the dominant ingredients in solid phase product after SCWO process were metals and glass fiber (e.g., $\mathrm{SiO}_{2}$ ).

To further find out the relevant information about the effect of SCWO conditions on the speciation of metals contained in waste PCBs, X-ray powder diffraction examinations of waste PCBs after 


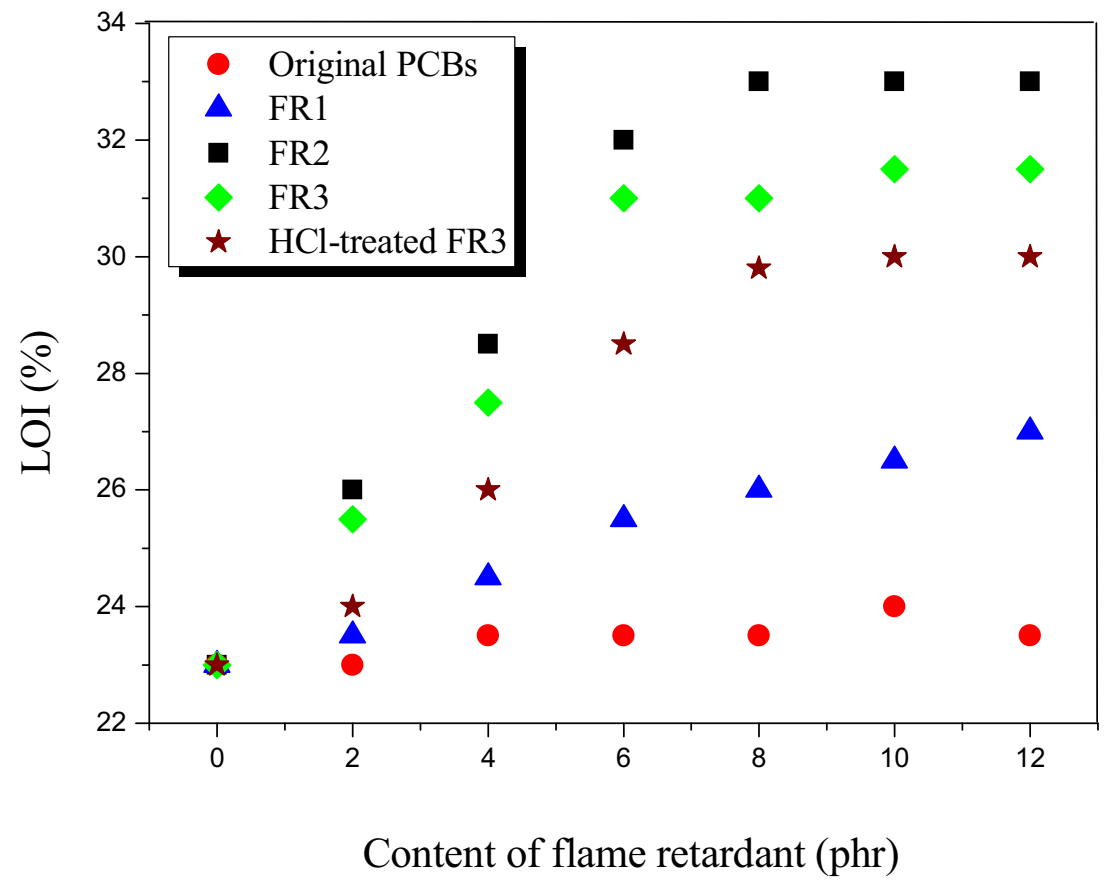

Fig. 2. Effect of flame retardant on the LOI of PVC sample (Flame retardant obtained from original waste PCBs, FR1, FR2, FR3, and HCl-treated FR3).

SCWO treatments with different conditions were performed. The XRD analytical results of FR1, FR2, and FR3 are showed in Fig. 1A-C, respectively. The main crystalline phases in FR1 were $\mathrm{Cu}, \mathrm{SnO}_{2}$, and $\mathrm{CuSn}$ alloy. The reaction condition of FR1 was subcritical water oxidation, under which $\mathrm{Sn}$ could be oxidized to $\mathrm{SnO}_{2}$ to a great extent, while $\mathrm{Cu}$ still existed as zero valent copper or formed alloy phase with Sn according to XRD result (Fig. 1A). However, when the SCWO temperature was increased to $420^{\circ} \mathrm{C}$ (FR2) and $460^{\circ} \mathrm{C}$ (FR3), which were under supercritical water conditions, $\mathrm{Cu}$ began to be oxidized to its oxides (Fig. 1B and C). Cu could be oxidized from $\mathrm{Cu}^{0}$ to the mixture of $\mathrm{Cu}^{+}\left(\mathrm{Cu}_{2} \mathrm{O}\right)$ and $\mathrm{Cu}^{2+}(\mathrm{CuO})$ when SCWO temperature was controlled at $420^{\circ} \mathrm{C}$. In comparison, $\mathrm{Cu}^{0}$ could be oxidized completely to $\mathrm{Cu}^{2+}(\mathrm{CuO})$ when SCWO temperature was increased to $460{ }^{\circ} \mathrm{C}$. Hence, a conversion of $\mathrm{Cu}$ elements $\left(\mathrm{Cu}^{0} \rightarrow \mathrm{Cu}^{+} \rightarrow \mathrm{Cu}^{2+}\right)$ took place during SCWO process with the increase of reaction temperature.

\subsection{Effect of SCWO conditions on the flame retardant properties of SCWO-treated waste PCBS}

The waste PCBs used in this study contains resin which is treated by brominated flame retardant. If the brominated flame retardants are still in the solid phase of waste PCBs after SCWO treatment, it will play a role in the PVC as flame retardant. In order to rule out this point, the bromine content in the FR1, FR2, and FR3 was measured by an oxygen combustion bomb-ion chromatography. The bromine content in the FR1 was $0.2 \%$, and the bromine contents in FR2 and FR3 were unable to detect. Hence, the bromine contained in FR1 might play a role in the PVC as flame retardant, but the role was very weak due to the very low bromine content $(0.2 \%)$. No bromine could be detected in FR2 and FR3, indicating that proper SCWO reaction conditions could completely remove the bromine in waste PCBs.

To investigate the effect of SCWO conditions on the flame retardant properties of SCWO-treated PCBs, FR1, FR2, and FR3 were used to test. For comparison, the original waste PCBs was also used as flame retardant for PVC sample in this study. LOI and CY values of PVC samples were used to indicate the flame retardancy. From Figs. 2 and 3, it can be seen that there is almost no flame retardant effect for the original PCBs due to the unaltered LOI and CY values. Inversely, the separate addition of FR1, FR2, and FR3 could significantly increased the LOI and CY values, indicating that the near critical water oxidation treatment for waste PCBs was conducive to produce effective active ingredients and improve the flame retardant properties. FR1 was obtained by subcritical water oxidation $\left(300^{\circ} \mathrm{C}, 10 \mathrm{MPa}, 30 \mathrm{~min}\right.$ ) of waste $\mathrm{PCBs}$, in which $\mathrm{SnO}_{2}$ was formed and copper existed as $\mathrm{Cu}^{0}$ or CuSn alloy according to XRD analysis result (Fig. 1A). The flame retardant property of FR1 might originate from $\mathrm{SnO}_{2}$ contained in FR1. Many studies [20,21] have found that tin compounds can be used as flame retardants in polymer materials, and the role of tin compounds occurred mainly in condensed phase. $\mathrm{SnO}_{2}$ could effectively catalyze the removal reaction of $\mathrm{HCl}$ from PVC [32]. The rapid release of $\mathrm{HCl}$ could dilute the oxygen around to a certain degree, and have some flame-retardation effects in gas phase.

With the increase of reaction temperature, FR2 and FR3 were obtained after SCWO treatment of waste PCBs. From Figs. 2 and 3, it can be seen that SCWO conditions have a remarkable influence on the flame retardant properties of the obtained product. The LOI and CY values of PVC samples adding FR2 and FR3 were all much higher than that of PVC samples adding FR1. Judging from the composition, the crystalline phase of CuSn alloy disappeared from the XRD pattern in Fig. $1 \mathrm{~B}$ and $\mathrm{C}$, indicating the increase of active ingredients content due to the further oxidation of $\mathrm{Sn}$ in CuSn alloy to $\mathrm{SnO}_{2}$. However, the Sn content only increased from $4.8 \%$ in FR1 to $6.1 \%$ in FR2 and $7.2 \%$ in FR3, respectively. Such a small amount of $\mathrm{SnO}_{2}$ is hard to be used to explain such a significant increase of LOI and CY values of PVC samples contained FR2 or FR3. Therefore, there must be other reasons. The most important reason for the enhancement of flame retardant and smoke suppression property of FR2 and FR3 seems to be the transformation of copper contained in waste PCBs. Copper was oxidized from $\mathrm{Cu}^{0}$ to the mixture of $\mathrm{Cu}_{2} \mathrm{O}$ and $\mathrm{CuO}$ at $420^{\circ} \mathrm{C}$ (Fig. 1B), and was completely oxidized to $\mathrm{CuO}$ at $460^{\circ} \mathrm{C}$ (Fig. 1C). Oxides of copper could react with $\mathrm{HCl}$ and promote the removal reaction of $\mathrm{HCl}$ from PVC. The reactions can be expressed as follows:

$\mathrm{CuO}+2 \mathrm{HCl} \rightarrow \mathrm{CuCl}_{2}+\mathrm{H}_{2} \mathrm{O}$ 


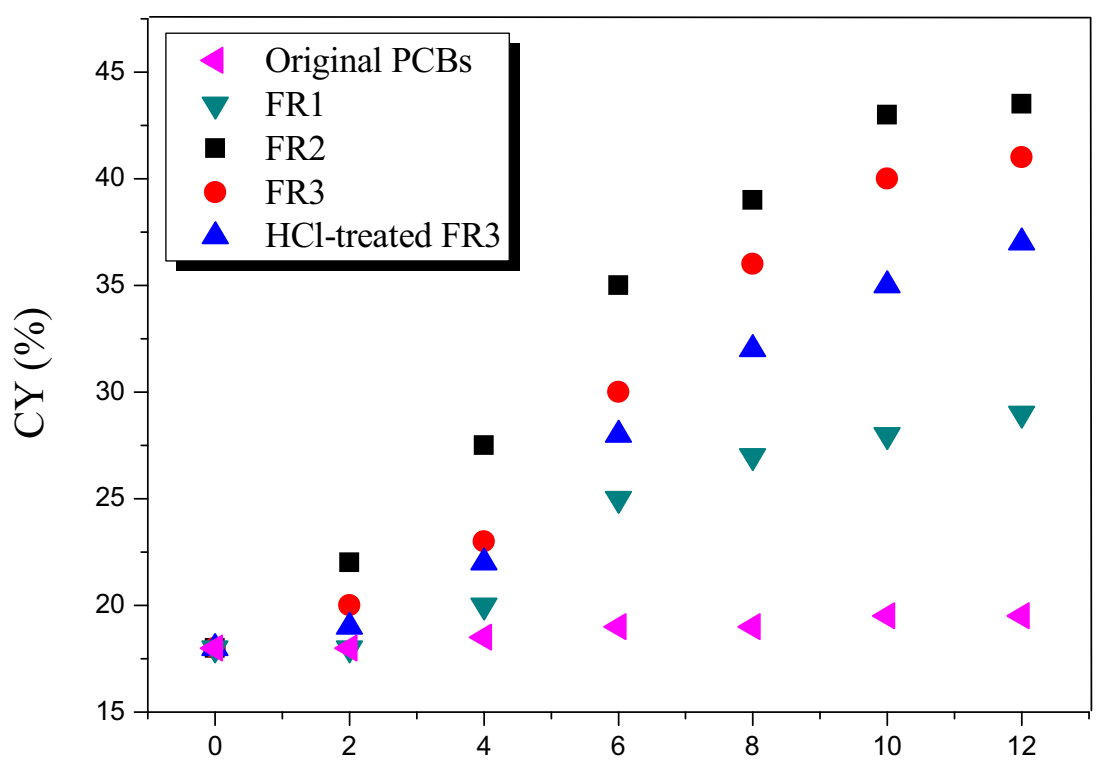

Content of flame retardant (phr)

Fig. 3. Effect of flame retardant on the CY of PVC sample (Flame retardant obtained from original waste PCBs, FR1, FR2, FR3, and HCl-treated FR3).

$\mathrm{Cu}_{2} \mathrm{O}+2 \mathrm{HCl} \rightarrow 2 \mathrm{CuCl}+\mathrm{H}_{2} \mathrm{O}$

The released $\mathrm{HCl}$ from PVC and the produced $\mathrm{H}_{2} \mathrm{O}$ could dilute the oxygen around and have flame-retardation effects in gas phase. The content of copper existed as oxides in FR2 or FR3 reached up to $32.7 \%$, which could be regarded as a key factor for the great flame retardant property of PVC samples adding FR2 or FR3.

It was interesting that the SCWO reaction temperature of FR3 $\left(460^{\circ} \mathrm{C}\right)$ was higher than that of FR2 $\left(420^{\circ} \mathrm{C}\right)$, but contrary to what one might suppose, the flame retardant property of FR3 was obviously lower than that of FR2 (Figs. 2 and 3). It seemed that the flame retardant property of the mixture of $\mathrm{Cu}_{2} \mathrm{O}$ and $\mathrm{CuO}$ were superior to that of single $\mathrm{CuO}$. We speculated that there might be a synergistic effect of flame retardancy between $\mathrm{Cu}_{2} \mathrm{O}$ and $\mathrm{CuO}$. It can be found from Table 1 that main metals (especially $\mathrm{Cu}$ and $\mathrm{Sn}$ ) contents in FR2 and FR3 were consistent, indicating that the amounts of $\mathrm{Cu}$ and $\mathrm{Sn}$ in FR2 and FR3 were unchanged, and the only thing that changed was the valence state of $\mathrm{Cu}$ according to XRD analysis results (Fig. 1B and C). It is well known that $\mathrm{Cu}^{+}$is unstable and the disproportion reaction of $\mathrm{Cu}^{+}$can produce $\mathrm{Cu}^{0}$ and $\mathrm{Cu}^{2+}$. The fresh $\mathrm{Cu}^{0}$ produced from the disproportion reaction of $\mathrm{CuCl}$ generated by reaction (3) was also unstable and easily oxidized to $\mathrm{Cu}_{2} \mathrm{O}$ or $\mathrm{CuO}$ by oxygen, $\mathrm{CuCl}_{2}$ or other oxidizing species in the system such as $\mathrm{Fe}^{3+}$ and $\mathrm{Pb}^{4+}$. Fe and $\mathrm{Pb}$ contained in waste PCBs could be oxidized to high valence state species such as $\mathrm{Fe}_{2} \mathrm{O}_{3}$ and $\mathrm{PbO}_{2}$ during SCWO process [33,34], and the formed $\mathrm{Fe}_{2} \mathrm{O}_{3}$ and $\mathrm{PbO}_{2}$ could react with $\mathrm{HCl}$, which was derived from the dehydrochlorination of PVC, to produce oxidizing species $\left(\mathrm{Fe}^{3+}\right.$ and $\left.\mathrm{Pb}^{4+}\right)$. The relevant reactions can be expressed as follows:

$2 \mathrm{Cu}^{+} \rightarrow \mathrm{Cu}^{0}+\mathrm{Cu}^{2+}$

$2 \mathrm{Cu}^{0}+\mathrm{O}_{2}+2 \mathrm{Cu}^{2+}\left(\mathrm{CuCl}_{2}\right) \rightarrow 2 \mathrm{Cu}_{2} \mathrm{O}$

$3 \mathrm{Cu}^{0}+\mathrm{O}_{2}\left(\mathrm{Fe}^{3+}, \mathrm{Pb}^{4+}\right) \rightarrow \mathrm{Cu}_{2} \mathrm{O}+\mathrm{CuO}$

The regenerated $\mathrm{Cu}_{2} \mathrm{O}$ or $\mathrm{CuO}$ could continue to conduct the Reaction (2) and (3). Therefore, the superior flame retardant property of FR2 might be attributed to the coexisting of $\mathrm{Cu}_{2} \mathrm{O}$ and $\mathrm{CuO}$ and their synergistic effect.
However, it is not clear whether there is a synergistic effect between oxides of copper and $\mathrm{SnO}_{2}$ in FR2 or FR3. Although the flame retardant property of FR3 was inferior to that of FR2, the property of FR3 was much better than that of FR1 (Figs. 2 and 3), indicating that the coexisting of $\mathrm{SnO}_{2}$ and $\mathrm{CuO}$, which was derived from the complete oxidation of copper, still showed higher flame retardant activity. To further confirm the positive effect of $\mathrm{CuO}$, a sample from which the $\mathrm{CuO}$ contained in FR3 was removed was prepared to evaluate the effect of $\mathrm{CuO}$. This sample was prepared by leaching out $\mathrm{CuO}$ from FR3 using $1 \mathrm{M}$ hydrochloric acid solution for $2 \mathrm{~h}$. This sample is termed "HCl-treated FR3". The XRD analysis result of $\mathrm{HCl}$-treated FR3 is showed in Fig. 1D. The main crystalline phase was $\mathrm{SnO}_{2}$, and the weak $\mathrm{CuO}$ diffraction peak indicated that vast majority of $\mathrm{CuO}$ was removed by hydrochloric acid. The metals contents in $\mathrm{HCl}$-treated FR3 were determined and the results were presented in Table 1 . Sn (15.1\%) tops the list of metals contents, followed by $\mathrm{Cu}(0.2 \%)$. With the removal of $\mathrm{CuO}$, the flame retardant property of $\mathrm{HCl}$-treated FR3 decreased significantly when compared to FR3 (Figs. 2 and 3). It is concluded that the CuO in FR3 play an important role with $\mathrm{SnO}_{2}$ in the flame retardant property of FR3.

\subsection{Effect of the dosage of SCWO-treated waste PCBs on the flame retardancy and smoke suppression of PVC samples}

From Fig. 2, it can be seen that the LOI values of PVC increase with increasing the dosage of SCWO-treated PCBs. In comparison with PVC with FR2, FR3, and HCl-treated FR3, the effect of dosage on the LOI value of PVC with FR1 was much smaller, the LOI value just increased from 23\% (no FR1 added) to 27\% (12 phr FR1 added). The possible reason is the lower content active ingredients and the higher content organics residual contained in FR1. Although the content of copper in FR1 (27.7\%) was much higher than that in $\mathrm{HCl}$-treated FR3 (0.2\%), the copper in FR1 existed as $\mathrm{Cu}^{0}$ and $\mathrm{CuSn}$ alloy which almost had no flame retardant abilities. In addition, the content of organics residual in FR1, FR2, FR3, and HCl-treated FR3 was determined, and the result was $12.1,0.2,0.1$, and $0.1 \%$, respectively. Obviously, the preparation condition of FR $1\left(300^{\circ} \mathrm{C}, 10 \mathrm{MPa}\right.$, $30 \mathrm{~min}$ ) could not completely remove the resin materials, and such 


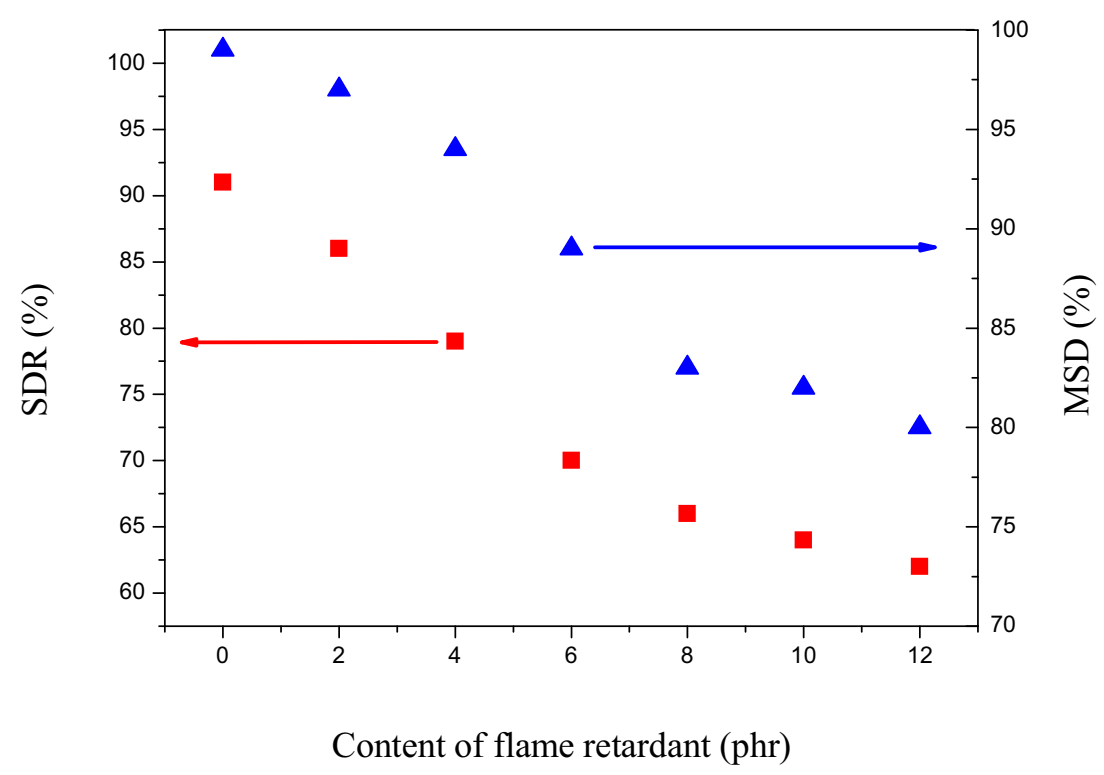

Fig. 4. Effect of FR2 on the SDR and MSD of PVC sample.

high levels of organics residual in FR1 had inevitably a negative influence on the flame retardant property of FR1.

The effect of the dosage of SCWO-treated waste PCBs on the CY of PVC is showed in Fig. 3. The CY of PVC with FR2 significantly increased with increasing the dosage of FR2. The CY increased from 18\% (PVC with no flame retardant) to $43.5 \%$ (10 phr FR2 added). However, for the PVC with FR1, FR3, and HCl-treated FR3, when the content of flame retardant $<6 \mathrm{phr}$, the CY of PVC sample changed a little. For instance, the CY of PVC with FR1 only increased from $18 \%$ (PVC with no flame retardant) to $20 \%$ ( 4 phr FR1 added). This may be due to the higher content organics residual contained in FR1 $(12.1 \%)$. The CY can be used as an important indicator for the function of char forming. The higher $\mathrm{CY}$ value means higher function of char forming during the combustion of PVC. From Fig. 3, it can be found that the increase of flame retardant content in PVC can lead to the increase of char yield and the higher function of char forming, which is highly favorable for improving the LOI value of PVC and enhancing the flame retardant property (Fig. 2).

To investigate the effect of the dosage of SCWO-treated PCBs on the smoke suppression performance of PVC, the SDR and MSD were measured. FR2 was used here due to its highest flame retardant efficiency among our prepared flame retardants. The results are presented in Fig. 4. The SDR and MSD of PVC with FR2 significantly decreased with increasing FR2 content. The SDR of PVC decreased to $70 \%$ when 6 phr FR2 was added. The smoke suppression standard of flame retardant for building materials in China is SDR $\leq 75 \%$. This may be due to the great enhancing of char forming function when the FR2 content added exceeds 6 phr, the CY of PVC with FR2 could reach up to $35 \%$ (Fig. 3 ). The enhancing of char forming function could significantly suppress the generation of smoke. The MSD value of PVC in Fig. 4 could also show the above changes. On the other hand, $\mathrm{Cu}_{2} \mathrm{O}$ contained in $\mathrm{FR} 2$ could be transformed into $\mathrm{CuCl}$ during the combustion of PVC according to the above discussions. $\mathrm{CuCl}$ could efficiently absorb poisonous gas such as $\mathrm{CO}$ and generate $\mathrm{Cu}_{2} \mathrm{Cl}_{2}(\mathrm{CO})_{2}$. Thus, the $\mathrm{Cu}_{2} \mathrm{O}$ contained in FR2 might also be an important reason for the great smoke suppression performance.

Thermogravimetric analysis can reveal the thermal properties and the degradation process of polymer, and provide the information of flame-retardant mechanism [21]. The TG curve of PVC with no flame retardant is shown in Fig. 5A. The thermal degradation weightlessness of PVC can be divided into three stages. The first stage of the degradation weightlessness occurred in the tem- perature interval of $200-350^{\circ} \mathrm{C}$. At this stage, the main reaction occurred were the removal of $\mathrm{HCl}$ from $\mathrm{PVC}$ and the decomposition of DOP. The weight loss was very obvious at the first stage and the percentage of weight loss exceeded 65\%. Compared with the PVC with no flame retardant added, PVC with 6 phr waste PCBs-derived flame retardant, especially FR2, had the much steeper slope for the weightlessness curve (Fig. 5B-D), indicating the faster weightlessness reaction speed. In addition, the temperature range of weight loss for the PVC with no flame retardant added was $200-350^{\circ} \mathrm{C}$. However, when 6 phr FR2 was added, the temperature range of weight loss for PVC was narrowed down, and the thermal degradation weightlessness was completed when the temperature was increased to $320^{\circ} \mathrm{C}$. All of the above results indicated that waste PCBs-derived flame retardant, especially FR2 had a significant catalytic and facilitative role for the removal of $\mathrm{HCl}$ from $\mathrm{PVC}$ at the first stage of degradation weightlessness. The rapid removal of $\mathrm{HCl}$ in PVC could facilitate the early cross-linking and char-forming in the first stage, and increase the LOI and CY value (Figs. 2 and 3).

The temperature range of weight loss for the second and third stage is around $430-650^{\circ} \mathrm{C}$. Compared to the weight loss rate and mass loss of the first stage, it is much smaller for those of the second and third stage. It can be found from Fig. 5 that after the adding of FR2, the temperature range of weight loss for the third stage (Fig. $5 \mathrm{C}$ ) becomes wider obviously when compared to that of the PVC with no flame retardant added (Fig. 5A). The temperature range of weight loss was broadened from 520 to $600^{\circ} \mathrm{C}$ for PVC with no flame retardant added to $520-640^{\circ} \mathrm{C}$ for PVC with 6 phr FR2 added. The broadening of temperature range of weight loss in the third stage indicated that the thermostability of the formed char was improved significantly with the adding of FR2, thus the flame retardant and smoke suppression performance of the PVC were enhanced.

\subsection{Effect of SCWO-treated PCBs on the mechanical property of PVC samples}

The mechanical properties such as tensile strength and impact strength of PVC containing FR2 with different content were tested. In addition, the elongation at break was also calculated. The results are shown in Table 2 . The tensile strength decreased with increasing the content of FR2. In particular, the tensile strength declined obviously when the additive amount of FR2 was higher than 6 phr. 

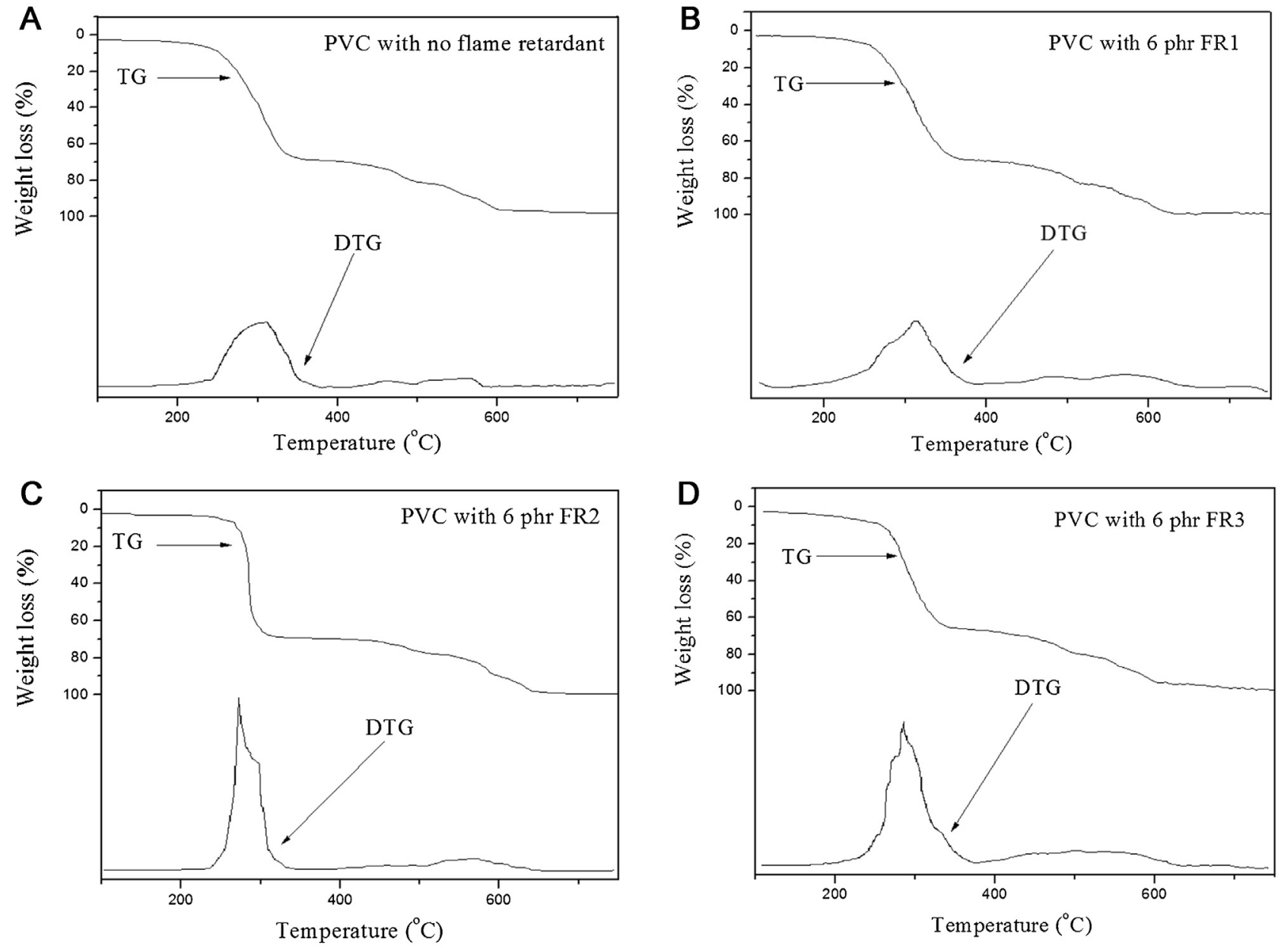

Fig. 5. TG and DTG analysis results of (A) PVC with no flame retardant and (B) PVC with 6 phr FR2.

Table 2

Effect of FR2 on the mechanical property of PVC samples (Basic recipe of PVC sample: PVC 100 phr, DOP 40 phr, stabilizer 3 phr, lubricant 1 phr).

\begin{tabular}{llll}
\hline FR2 (phr) & $\begin{array}{l}\text { Tensile strength } \\
(\mathrm{MPa})\end{array}$ & $\begin{array}{l}\text { Elongation at } \\
\text { break }(\%)\end{array}$ & $\begin{array}{l}\text { Impact strength } \\
\left(\mathrm{KJ} / \mathrm{m}^{2}\right)\end{array}$ \\
\hline 0 & 30.9 & 189 & 6.7 \\
2 & 29.9 & 196 & 6.7 \\
4 & 29.4 & 202 & 6.5 \\
6 & 28.9 & 194 & 6.5 \\
8 & 27.7 & 175 & 5.8 \\
10 & 26.5 & 168 & 5.2 \\
12 & 25.6 & 158 & 4.9 \\
\hline
\end{tabular}

However, the additive amount of FR2 had little impact on the tensile strength when the additive amount is small (for example, less than $6 \mathrm{phr}$ ). The tensile strength only decreased from 30.9 to $28.9 \mathrm{Mpa}$ when the additive amount was increased from 0 to 6 phr.

Both elongation at break and impact strength decreased obviously with the increase of FR2 when the FR2 amount was more than $6 \mathrm{phr}$, which was similar to the changing law of tensile strength. However, elongation at break and impact strength are at high values when the amount of FR2 is lower than 6 phr. By controlling appropriate adding amount, PVC samples could possess both good flame retardancy and satisfactory mechanical properties.

\section{Conclusions}

The adding of SCWO-treated PCBs could remarkably improve the flame retardancy and smoke suppression of PVC. $\mathrm{Cu}_{2} \mathrm{O}, \mathrm{CuO}$, and $\mathrm{SnO}_{2}$ were the main active ingredients of the waste PCBsderived flame retardant, and the conversion of $\mathrm{Cu}$ elements $\left(\mathrm{Cu}^{0} \rightarrow \mathrm{Cu}_{2} \mathrm{O} \rightarrow \mathrm{CuO}\right)$ during SCWO process with the increase of reaction temperature played a positive role in improving the flame retardancy and smoke suppression of PVC. The SCWO-treated PCBs containing the mixture of $\mathrm{Cu}_{2} \mathrm{O} / \mathrm{CuO} / \mathrm{SnO}_{2}$ had the highest flame retardant and smoke suppression performance. The SCWO-treated PCBs had a significant catalysis and facilitation role for the removal of $\mathrm{HCl}$ from PVC at the first stage of degradation weightlessness. The rapid removal of $\mathrm{HCl}$ in PVC could facilitate the early crosslinking and char-forming in the first stage, and increase the LOI and $\mathrm{CY}$ value. The temperature range of weight loss was broadened at the third stage of degradation weightlessness of PVC when SCWOtreated PCBs was added. The broadening of temperature range of weight loss in the third stage indicated that the thermostability of the formed char was improved significantly with the adding of SCWO-treated PCBs, thus the flame retardant and smoke suppression performance of PVC were enhanced.

The mechanical properties such as tensile strength, elongation at break, and impact strength of PVC were influenced in different degree by adding different content SCWO-treated PCBs. By controlling appropriate adding amount, PVC could possess both good flame retardancy and satisfactory mechanical properties.

\section{Acknowledgements}

This research was financially supported by Program for New Century Excellent Talents in Fujian Province University (GY- 
Z15087), the Natural Science Foundation of Fujian Province (2014J01167 and 2015J01034), and the Scientific Research Foundation of Fujian University of Technology (GY-Z15094, GY-Z15097, GY-Z10054 and GY-Z10055).

\section{References}

[1] J. Wang, Z. Xu, Disposing and recycling waste printed circuit boards: disconnecting, resource recovery, and pollution control, Environ. Sci. Technol. 49 (2015) 721-733

[2] B. Ghosha, M.K. Ghosh, P. Parhi, P.S. Mukherjee, B.K. Mishra, Waste printed circuit boards recycling: an extensive assessment of current status, J. Clean. Prod. 94 (2015) 5-19.

[3] C.L. Duan, Z.J. Diao, Y.M. Zhao, W. Huang, Liberation of valuable materials in waste printed circuit boards by high-voltage electrical pulses, Miner. Eng. 70 (2015) 170-177.

[4] M. Xing, F.-S. Zhang, Degradation of brominated epoxy resin and metal recovery from waste printed circuit boards through batch sub/supercritical water treatments, Chem. Eng. J. 219 (2013) 131-136.

[5] S. Fogarasi, F. Imre-Lucaci, Á. Imre-Lucaci, P. Ile, Copper recovery and gold enrichment from waste printed circuit boards by mediated electrochemical oxidation, J. Hazard. Mater. 273 (2014) 215-221.

[6] J. Moltó, S. Egea, J.A. Conesa, R. Font, Thermal decomposition of electronic wastes: mobile phone case and other parts, Waste Manag. 31 (2011) 2546-2552.

[7] A. Tuncuk, V. Stazi, A. Akcil, E.Y. Yazici, H. Deveci, Aqueous metal recovery techniques from E-scrap: hydrometallurgy in recycling, Miner. Eng. 25 (2012) 28-37.

[8] Y. Yang, S. Chen, S. Li, M. Chen, H. Chen, B. Liu, Bioleaching waste printed circuit boards by Acidithiobacillus ferrooxidans and its kinetics aspect, J. Biotechnol. 173 (2014) 24-30.

[9] K. Huang, J. Guo, Z. Xu, Recycling of waste printed circuit boards: a review of current technologies and treatment status in China, J. Hazard. Mater. 164 (2009) 399-408.

[10] J. Li, H.Z. Lu, J. Guo, Z.M. Xu, Y.H. Zhou, Recycle technology for recovering resources and products from waste printed circuit boards, Environ. Sci. Technol. 41 (2007) 1995-2000.

[11] Q.J. Guo, X.H. Yue, M.H. Wang, Y.Z. Liu, Pyrolysis of scrap printed circuit board plastic particles in a fluidized bed, Powder Technol. 198 (2010) 422-428.

[12] F. Barontini, V. Cozzani, Formation of hydrogen bromide and organobrominated compounds in the thermal degradation of electronic boards, J. Anal. Appl. Pyrol. 77 (2006) 41-55.

[13] H.L. Chiang, K.H. Lin, Exhaust constituent emission factors of printed circuit board pyrolysis processes and its exhaust control, J. Hazard. Mater. 264 (2014) 545-551.

[14] N. Li, X. Lu, S. Zhang, A novel reuse method for waste printed circuit boards as catalyst for wastewater bearing pyridine degradation, Chem. Eng. J. 257 (2014) 253-261.

[15] P. Hadi, P. Gao, J.P. Barford, G. McKay, Novel application of the nonmetallic fraction of the recycled printed circuit boards as a toxic heavy metal adsorbent, J. Hazard. Mater. 252-253 (2013) 166-170.

[16] M. Xu, P. Hadi, G. Chen, G. McKay, Removal of cadmium ions from wastewater using innovative electronic waste-derived material, J. Hazard. Mater. 273 (2014) 118-123.
[17] P. Hadi, J. Barford, G. McKay, Toxic heavy metal capture using a novel electronic waste-based material-mechanism, modeling and comparison, Environ. Sci. Technol. 47 (2013) 8248-8255.

[18] W-K. Ho,J.K. Walker S.V. Orski, T.W. Fuller, A.G. Zestos, C.L Grinnell, R.D. Pike, J.W.H. Starnes, A new synergistic effect in the smoke suppression of plasticized poly(vinyl chloride) by mixed-metal Cu(II) oxides, J. Vinyl Add. Technol. 14 (2008) 16-20.

[19] B. Li, A study of the thermal decomposition and smoke suppression of poly (vinyl chloride) treated with metal oxides using a cone calorimeter at a high incident heat flux, Polym. Degrad. Stab. 78 (2002) 349-356.

[20] P.A. Atkinson, P. Haines, G.A. Skinner, Inorganic tin compounds as flame retardants and smoke suppressants for polyester thermosets, Thermochim. Acta 360 (2000) 29-40.

[21] H. Qu, W. Wu, Y. Zheng, J. Xie, J. Xu, Synergistic effects of inorganic tin compounds and $\mathrm{Sb}_{2} \mathrm{O}_{3}$ on thermal properties and flame retardancy of flexible poly (vinyl chloride), Fire Saf. J. 46 (2011) 462-467.

[22] J. Jang, J. Kim, J.-Y. Bae, Synergistic effect of ferric chloride and silicon mixtures on the thermal stabilization enhancement of ABS, Polym. Degrad. Stab. 90 (2005) 508-514.

[23] M. Batistella, B. Otazaghine, R. Sonnier, A.-S. Caro-Bretelle, C. Petter, J.-M. Lopez-Cuesta, Fire retardancy of ethylene vinyl acetate/ultrafine kaolinite composites, Polym. Degrad. Stab. 100 (2014) 54-62.

[24] F. Bertini, M. Canetti, G. Audisio, G. Costa, L. Falqui, Characterization and thermal degradation of polypropylene-montmorillonite nanocomposites, Polym. Degrad. Stab. 91 (2006) 600-605.

[25] L. Clerc, L. Ferry, E. Leroy, J.M. Lopez-Cuesta, Influence of talc physical properties on the fire retarding behaviour of (ethylene-vinyl acetate copolymer/magnesium hydroxide/talc) composites, Polym. Degrad. Stab. 88 (2005) 504-511.

[26] T. Havlik, D. Orac, M. Petranikova, A. Miskufova, F. Kukurugya, Z. Takacova, Leaching of copper and tin from used printed circuit boards after thermal treatment, J. Hazard. Mater. 183 (2010) 866-873.

[27] Y.-C. Chien, H.P. Wang, K.-S. Lin, Y.W. Yang, Oxidation of printed circuit board wastes in supercritical water, Wat. Res. 34 (17) (2000) 4279-4283.

[28] Y. Matsumoto, Y. Oshima, Au and Cu recovery from printed boards by decomposition of epoxy resin in supercritical water, J. Supercrit. Fluids 95 (2014) 462-467

[29] F.-R. Xiu, Y. Qi, F.-S. Zhang, Leaching of Au, Ag, and Pd from waste printed circuit boards of mobile phone by iodide lixiviant after supercritical water pre-treatment, Waste Manag. 41 (2015) 134-141.

[30] J. Li, X. Xu, W. Liu, Thiourea leaching gold and silver from the printed circuit boards of waste mobile phones, Waste Manag. 32 (2012) 1209-1212.

[31] F.-R. Xiu, Y. Qi, F.-S. Zhang, Co-treatment of waste printed circuit boards and polyvinyl chloride by subcritical water oxidation: removal of brominated flame retardants and recovery of $\mathrm{Cu}$ and Pb, Chem. Eng. J. 237 (2014) 242-249.

[32] E.M. Bulewicz, P. Padley, Mechanism of $\mathrm{SnO}_{2}$ on flame retardant in polymer in: In: Proceeding of the ninth symposium on combustion, New York, Academic Press, 1963, pp. 53-56.

[33] F.-R. Xiu, F.-S. Zhang, Recovery of copper and lead from waste printed circuit boards by supercritical water oxidation combined with electrokinetic process, J. Hazard. Mater. 165 (2009) 1002-1007.

[34] F.-R. Xiu, F.-S. Zhang, Electrokinetic recovery of Cd, Cr, As, Ni, Zn and Mn from waste printed circuit boards: effect of assisting agents, J. Hazard. Mater. 170 (2009) 191-196 